\title{
An Assessment of Nutritional Status of Children of Government Aided Primary School of West Bengal
}

\author{
Tirtha Mondal $^{1, *}$, Samiran Mondal ${ }^{2}$, Malabika Biswas ${ }^{3}$ \\ ${ }^{1}$ Department of Physical Education, Birbhum Zilla School, West Bengal, India \\ ${ }^{2}$ Department of Physical Education, Visva Bharati University, West Bengal, India \\ ${ }^{3}$ Department of Physical Education, Abhedananda Mahavidyalaya, West Bengal, India
}

Email address:

tirtham2010@gmail.com (T. Mondal)

\section{To cite this article:}

Tirtha Mondal, Samiran Mondal, Malabika Biswas. An Assessment of Nutritional Status of Children of Government Aided Primary School of West Bengal. International Journal of Elementary Education. Vol. 4, No. 3, 2015, pp. 41-45. doi: 10.11648/j.ijeedu.20150403.11

\begin{abstract}
Low Nutritional status of Bengali Primary School Children was concluded by different authors for last two decades, but most of the study conducted in a specified part of the Bengal, India and conclusions were drawn accordingly. This study was carried out among 3654 primary school children, being aged 8-9 years from 183 schools of all districts of West Bengal State. Body height and Body weight measurements were recorded following standard techniques. The body mass index (BMI) was calculated following standard formula: $\mathrm{BMI}=\mathrm{Kg} / \mathrm{M}^{2}=$ Weight $(\mathrm{Kg}) / \mathrm{Height}\left(\mathrm{M}^{2}\right)$. Three commonly used under nutrition indicator i.e stunting, under weight and thinness were used to evaluate the nutritional status of the subjects. The study results, $26.1 \%$ boys and $22.9 \%$ girls were stunted, boys $39.7 \%$ and girls $36.5 \%$ were under weight and in thinness percentage of boys was $65.4 \%$ where as in girls it was $65.3 \%$.
\end{abstract}

Keywords: Nutritional Status, Height, Weight, BMI, Thinness, Stunting, Under Weight, Elementary School Children

\section{Introduction}

Over $1 / 5^{\text {th }}$ of our population compiles the children of age 5-12 years, i.e, Primary Education(1). As today's children are the citizen of tomorrow's world, their survival, protection and development are prerequisite for the future development of humanity (2). Nutrition has major effect on health. Nutrition refers to the availability of energy and nutrients to the body's cell in relation to body requirement. Malnutrition refers to any imbalance in satisfying nutrition requirements (3). In India national level data on child malnutrition have, however, been scarce. Recognizing their gap, India's 1992-93 National Family health Survey (NFHS) collected anthropometric data on height and weight of children and data shows that $53 \%$ of children in rural areas are underweight, and this varies across the states. The percentage of underweight children in the country was 53.4 in 1992 it decreased to 45.8 in 1998 and rose again in 2006. The report estimates level of children malnutrition and effect of selected demographic and socioeconomic factor.

A child entire life is determined in large measures by the food ginning to him/her in the first five year. Malnutrition among children is an important health problem in India including West Bengal. Anthropometric measurement is an almost mandatory tool in any research to assess health and nutritional condition in childhood. Physical measurement like body weight, height, circumference of arm and calf, triceps, skin fold etc. are extensively used to determine the nutritional status of children. Based on age, height, and weight, a number of indices such as height for age(stunting), weight for age (underweight) and BMI for age (Thinness) have been suggested. Stunting is defined as a low height-for-age for children, and measures the past (chronic) child undernutrition. Children with $\mathrm{Z}$ scores $<-2.00$ are said to be stunted and those $<-3.00$ severely stunted. Underweight is defined as low weight- for-age and it reflects past (chronic) and present (acute) undernutrition. Children with $\mathrm{Z}$ scores $<-2.00$ are said to be underweight. Thinness is BMI for age. Thinness refers to a human who is considered to be under a normal BMI for age and it is graded as III, II,I (severe, moderate and mild respectively) defined to pass through BMI value of 16.0,17.0, and $18.5 \mathrm{Kg} / \mathrm{M}^{2}$ respectively.

There is little information on health and nutritional status of West Bengal Primary School Children. Most of the study focus in a particular district in this state but this state compiles hill, terai, dooars and oceanic region. So, it is quite difficult to make any general conclusion regarding the health 
and nutritional status of the children. This, perhaps, holds good especially for the state like West Bengal which is a border state and densely-populated state. There for the major objectives of the study is to study the West Bengal primary school children's health status, specially stunting, (height for age), underweight (weight for age) and thinness (BMI for age) variables.

\section{Methods}

This was a cross-sectional survey study. The researcher selected her own state West Bengal, India, for this study West Bengal(WB) is situated in the eastern region of India and is the nation's fourth most populous state. It is also the seventh most populous sub-national entity in the world. West Bengal, together with Bangladesh lying on its east, forms the historical and geographical region of Bengal. To its northeast lie the states of Assam and Sikkim and the country of Bhutan, and to its southwest lies the state of Orissa. To the west, it borders the states of Jharkhand and Bihar, and to the northwest, Nepal. The total area of the state is $88,752 \mathrm{sq} \mathrm{km}$. According to the census of 2001, the state has a population of $8,02,21,171$. West Bengal's climate composes of four main seasons viz. summer, monsoon, a short autumn, and winter. The delta region experiences more humidity in the atmosphere during summer season; the western highlands experience a dry summer, with day temperature ranging from $38^{\circ} \mathrm{C}$ to $45^{\circ} \mathrm{C}$. The nights are comparatively cool carrying moisture from the Bay of Bengal. The winter session starts from October and continues till February. The climate of the northern region during winter months is pleasant but there is heavy snowfall in the Himalayan regions. In this state, east, west north, south and middle part are different in each and every nature, so that the researcher selected all 19 districts in West Bengal state of India.

According to the Elementary Education Reports (2006-07) that in West Bengal the number of government aided primary school was 59737. The total number of primary schools in each district of West Bengal is as follows.

Table 1. District wise primary schools in West Bengal State (2006-07)

\begin{tabular}{|c|c|c|c|c|c|c|c|c|}
\hline SI No. & District Name & No of School & SI No. & District Name & No of School & SI No. & District Name & No of School \\
\hline 1 & Bankura & 3917 & 8 & Jalpaiguri & 2833 & 15 & Paschim midnapur & 5398 \\
\hline 2 & Burddhaman & 5856 & 9 & Koochbihar & 2103 & 16 & Purba midnapur & 3913 \\
\hline 3 & Birbhum & 2784 & 10 & Kolkata & 2099 & 17 & Purulia & 3334 \\
\hline 4 & Daxin dinajpur & 1368 & 11 & Maldah & 2219 & 18 & South 24 pgs & 4455 \\
\hline 5 & Darjeeling & 0914 & 12 & Murshidabad & 3690 & 19 & Uttar dinajpur & 1656 \\
\hline 6 & Howrah & 2639 & 13 & Nadia & 3126 & & & \\
\hline 7 & Hoogli & 3659 & 14 & North 24pgs & 4774 & & & \\
\hline
\end{tabular}

From each district, 10 schools were selected by the method of cluster random sampling. So, from total 19 districts 190 school $(19 \times 10)$ were selected. It should be mentioned here that due to political/ local disturbances 7 schools (3 schools at Darjeeling and 4 schools in South 24 Parganas) could not be attended. So, a total 183 schools were studied.

As per the Government of India data (NUPA-2005) the total number of primary school student in West Bengal was 12592333 (2005-06). From each selected school total 20 (10 boys and 10 girls) primary school students from senior classes (III \&IV) were randomly selected. Total number of subjects in a district $(10$ school $\times 20)=200$ and in the whole state $(19$ $\mathrm{X} 10 \mathrm{X} 20)=3800$ subjects was selected (Plate-3). But it should also mentioned here, in ground condition total 146 subjects could not turn up due to different reasons. So, the actual number of subjects in this study was 3654 (3800-146). The age range of subjects (Boys-1833 and girls1821) was 8-9 years.

Before collection of data, the researcher made an appeal to the West Bengal Primary Education Council (WBPEC), Bidhannagar, Kolkata, for an approval to collect data. It is worthy mentioning here that this project was approved by the National Council of Education Research and Training (NCERT), Govt. of India and the research scholar enjoyed a prestigious doctoral fellowship. All these two approval generating a high impact for the collection of data. Approval latter from NCERT and WBPEC presented below.

\subsection{Anthropometric Measurements}

Height, Weight measurements were taken by the researcher following the standard techniques. Weight and height were recorded with the subject wearing the school uniform (single cloth) to the nearest $0.5 \mathrm{~kg}$ and $0.1 \mathrm{~cm}$ respectively. The body mass index(BMI) was calculated following standard formula:

$$
\text { BMI9Kg/M² =Weight }(\mathrm{Kg}) / \operatorname{Height}\left(\mathrm{M}^{2}\right) \text {. }
$$

\subsection{Evaluation of Nutritional Status}

Three commonly used under nutrition indicators, i.e, stunting, under nutrition and thinness were used to evaluate the nutritional of the subjects. The United States National Centre for Health Statistics (NCHS) 17,18 age and sex specific $-2 \mathrm{Z}$ scores were followed to define underweight, stunting and thinness. The following scheme was utilized;

Stunting: < -2 HAZ(Z score for height for age)

Underweight: $<-2$ WAZ( Z score for weight for age)

Thiness: <-2 BMIZ( Z score for BMI for age)

Where WAZ,HAZ and BMIZ to height-for age, weight for - age and BMI - for - age , age and sex specific Z scores , respectively, of NCHS19. 


\section{Results}

Stunting is height for age. Stunting is a good objective health status measurer. It expresses the status of chronic malnutrition. In West Bengal, Primary School Student (III \& IV standard) $24.5 \%$ facing chronic malnutrition (Stunting). When were compared these results with boys and girls, it was found that, boys were $26.1 \%$ and girls were $22.9 \%$ in chronic malnourished condition. It should be mentioned here that $72.1 \%$ boys and $76.6 \%$ girls were in the normal category. The percentage value of stunting is presented separately for boys and girls in the plate no-1
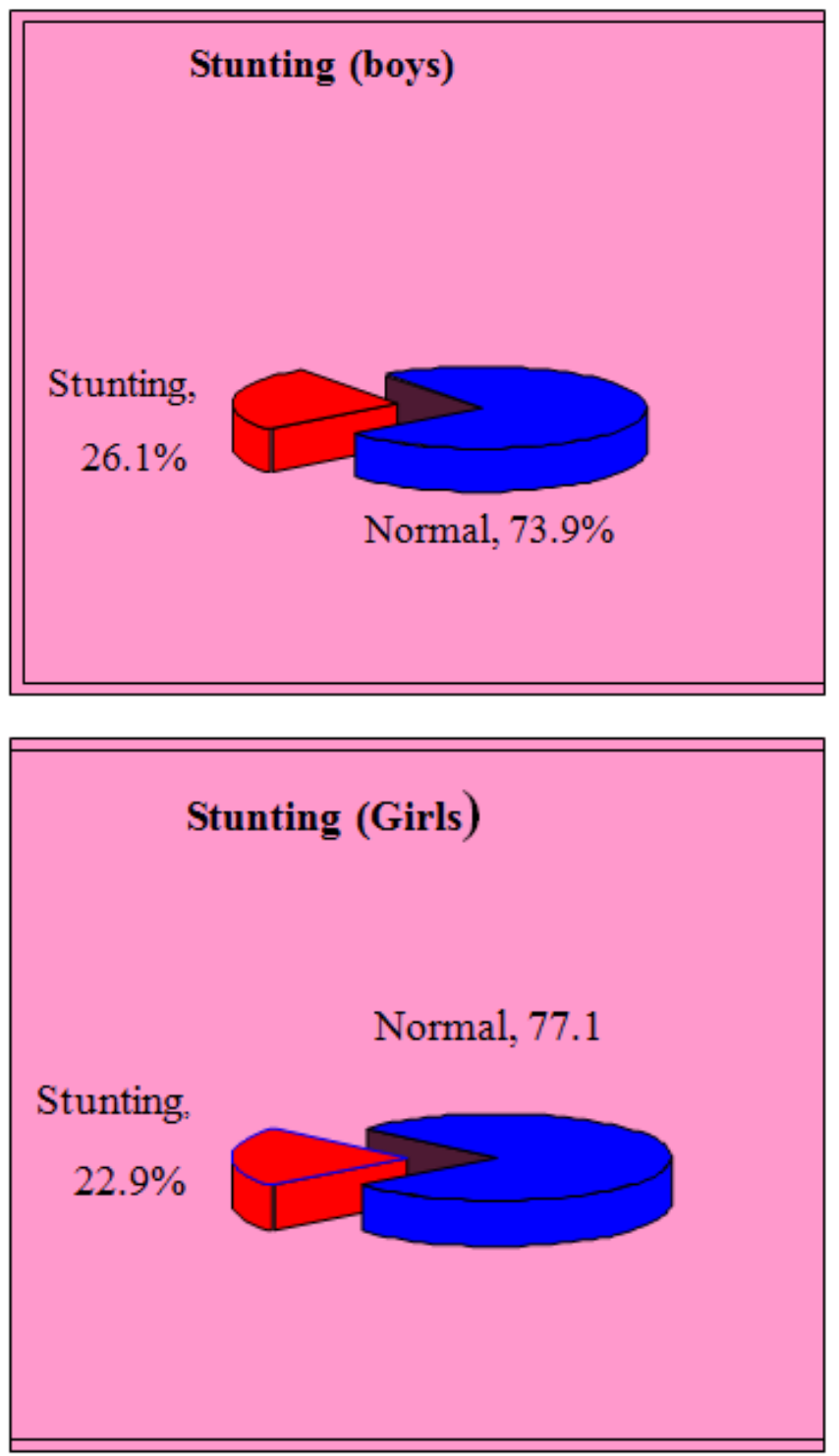

Plate No-1. Stunting for Boys and girls

\section{Under Weight}

Under weight is weight for age and an indicator of acute malnutrition. Under weight also is an objective health status measurer. In the present study, it was found overall state of acute malnutrition in the primary school boys and girls was $38.1 \%$. When it is considered respectively in the boys and girls category it was observed that in boys $39.7 \%$ and in girls $36.5 \%$ under weight. It is better to mention that in West Bengal $60.1 \%$ boys and $63.4 \%$ girls were under normal weight for age category. The under weight data reported for better understanding in the plate No-2
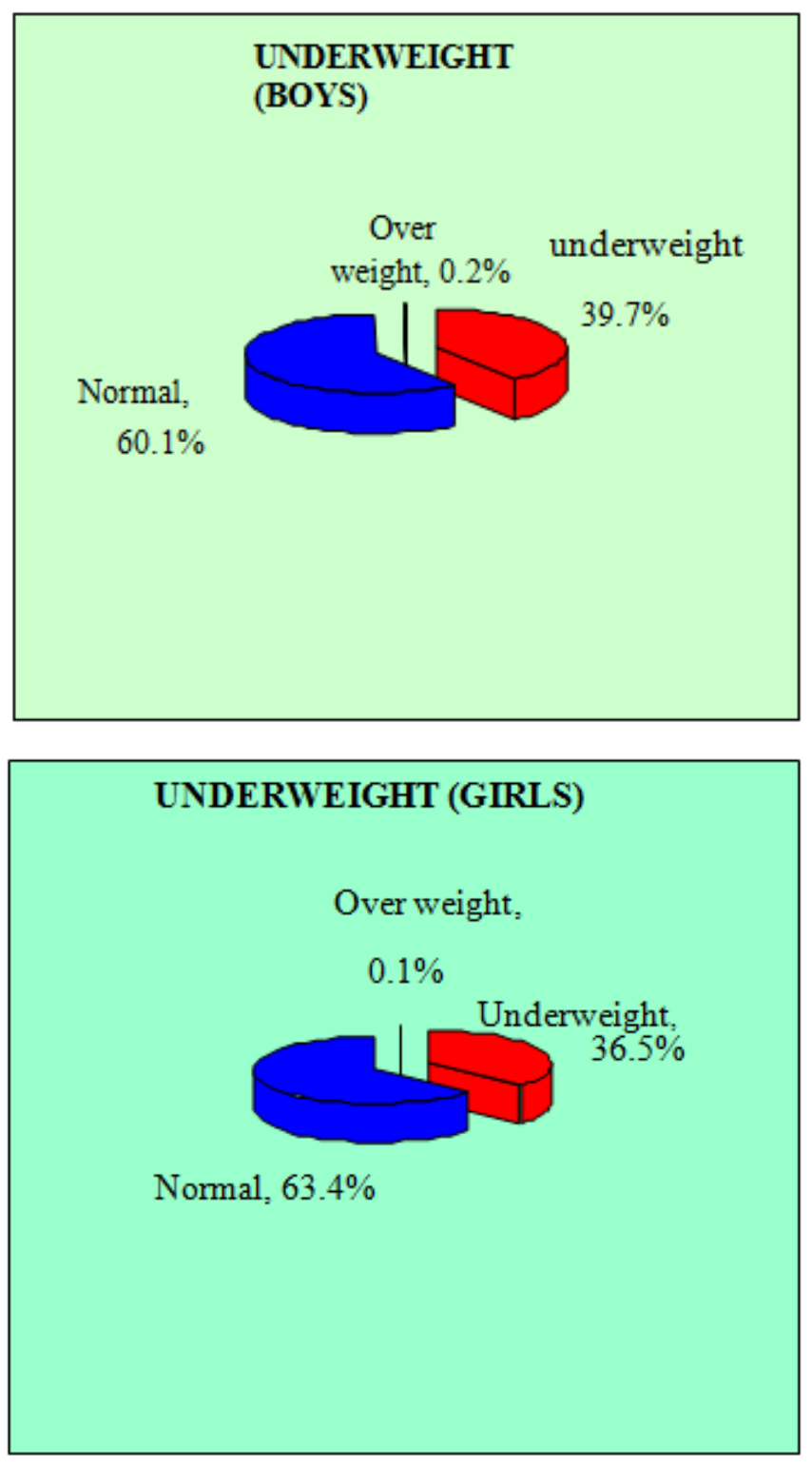

Plate No-2. Underweight for boys and girls

\section{Thinness}

Thinness is BMI for age. The term thinness refers to a human who is considered to be under a normal BMI for age. Recently it was developed by Cole et al. (2007). The overall thinness score of primary school student in West Bengal was $65.3 \%$ in the year of 2008-09. In thinness boys and girls trends were very similar. The thinness percentage in boys was $65.4 \%$ where as in girls it was $65.3 \%$. The pictorial percentage is given below in the plate No-3. 

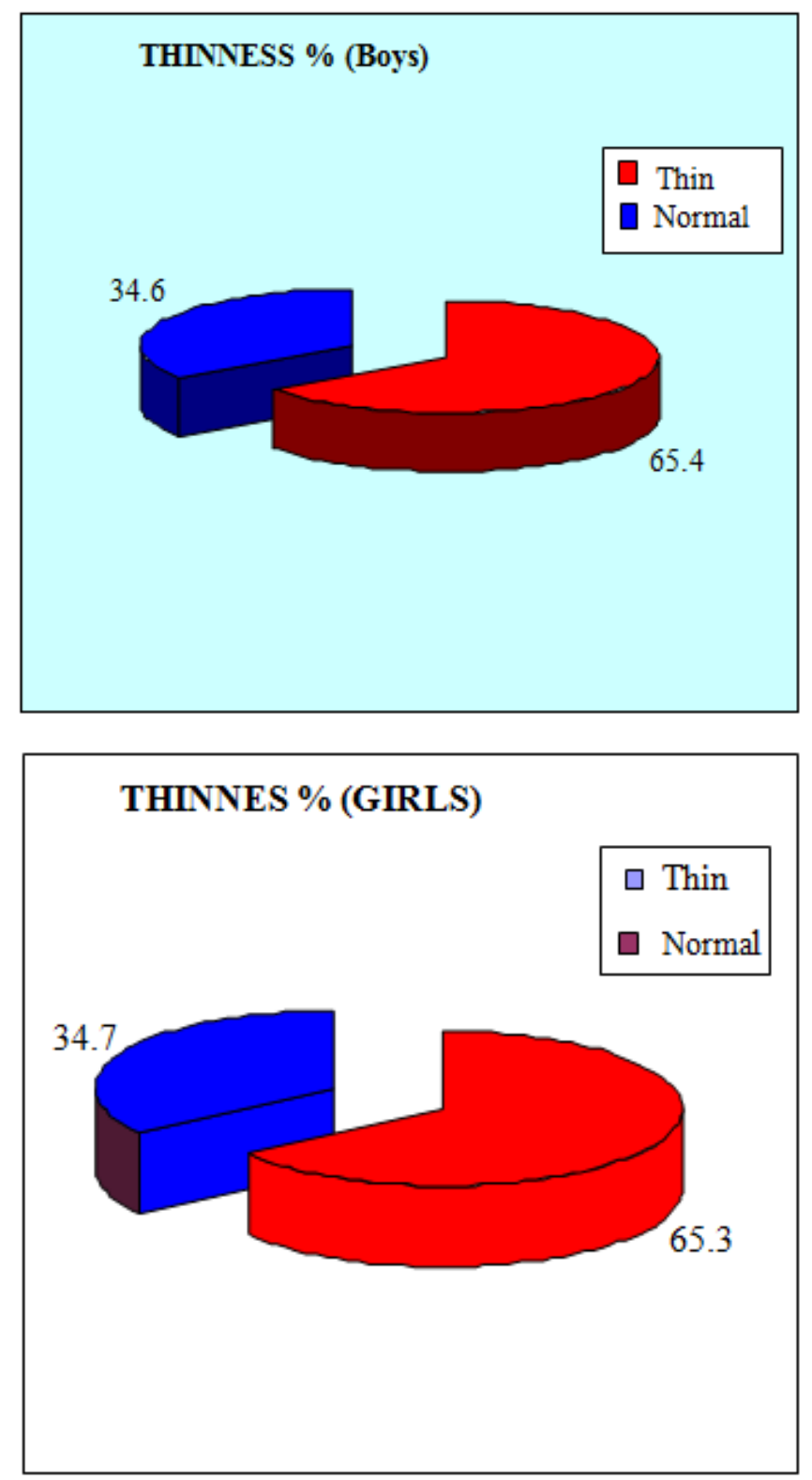

Plate No-3. Thinness for Boys and girls

\section{Discussion}

Improved child health and survival are considered as universal humanitarian goals. Malnutrition to be a problem of considerable magnitude in most developing countries of the world. Several studies have shown that dietary and environmental constraints are the major determinants of differences in the growth performance between children of developing and developed countries (Some et al. 2006; Rajaram et al.2003; Chatterjee 2007; Graitcer et al 1981. In the present study stunting, underweight and thinness were calculated for evaluating children nutritional status. Patil and Wasnic (2009) reported school children in Ratnagiri district of Maharastra state, India. They observed that in the age of 8 years underweight, stunting and thinness were $13.0 \%, 11.2 \%$ and $10.6 \%$ and in the age of 9 years it was $10.8 \%, 6.0 \%$ and $9.1 \%$ respectively. Bose et al (2008) reported nutritional status of rural school children in Bankura district, West Bengal, India. They observed in the age of 8 years children were facing underweight $10.7 \%$, stunting $7.1 \%$ and thinness $21.4 \%$. In the age of 9 years they found underweight $10.9 \%$, stunting $9.1 \%$ and thinness $12.7 \%$.This study provided evidence that these children were acute and chronic nutritional stress indicating the requirement of immediate appropriate public health nutritional intervention programmes. This has important implications for public health policy-maker, planners and organizations seeking to meet national and international developmental targets. However, it must be noted here that the conclusion drown may not be applicable for all district of India, but to a certain extent it may be true for West Bengal state. Medhi et al (2006) observed growth and nutritional status of 6-14 years children of tea garden worker of Assam. They reported in the age of 8 years overall stunting, underweight were $46.6 \%$ and $51.1 \%$ respectively and in the age of 9 years stunting and thinness were $46.5 \%$ and $55.5 \%$ respectively. Stunting (Height for age) reflects a failure to reach the linier growth potential due to sub-optimal health and /or nutritional conditions. Underweight reveals a low body mass relative to chronological age, which is influence by both a child's height and weight.

In the present study, the researcher observed that in the average age of 8.5 years (8-9yrars) the stunting $24.5 \%$, underweight $38.1 \%$ and thinness was $65.3 \%$. From this data, it may be revealed that in the Indian context particularly in West Bengal, the primary school children were facing a serious malnutrition problem. For developing a nation and particularly to develop as a sporting nation, getting the best result in each and every games and sports in the world arena, it must overcome this primary level malnutrition problem.

\section{References}

[1] Anonymous. WHO Research to improve implementation and effectiveness of school health programme, Geneva, WHO ,1996:1,9,10-15.

[2] Bakhetia P and Jain R. Anthropometric Profile And Physical Performance Of Rural School Girls. Anthropologist. 2007; 9(2):139-141.

[3] Bharati P, Sunanda I, Megeri SN. Anthropometric measurements of school children of Raichur. J Hum. Ecol. 2005; 18 (3):177-179.

[4] Bisai S, Bose K, Ghosh A. Nutritional Status Of Lodha Children in village of Paschim Midnapur District, West Bengal. Indain journal of public health. 2008; (52): 4.

[5] Bose K, Bhunia D, Paul G, Mukhopadhaya A, Chokarborty R. Primary School Children of East Midnapore District, West Bengal, India. Human Ecology Special Issue.2006; (14):71-75.

[6] Bose K, Bisai S, Mukherjee S, Anthropometric characteristics and nutritional status of rural school children. The Internet Journal of Biological Anthropology. 2008; (2)1.201-05. 
[7] Bose K, Bisai S, Mukhopadhyay A, Bhadra M. Overweight and obesity among affluent Bengali schoolgirls of Lake Town, Kolkata, India. Matern Child Nutr. 2007; 3(2):141-5.

[8] Chakraborty R, Bose K, Khongsdier R, Bisai S. Body mass index and body fat among adult Bengalee male slum dwellers in West Bengal, India. Journal of Public Health.2009; 17(5): 301-308.

[9] Chandra S, Sehgal A. Prevalence of deficiency diseases among school children. health and population Perpectives and issue. $1994 ; 17(1 \& 2): 108-113$.

[10] Chaterjee P. Child malnutrition rises in India despite economic boom. The Lancet. 2007; 369: 1417-18.

[11] Chowdhury SD, Chakraborti T, Ghosh T. Fat patterning of Santhal children: a tribal population of West Bengal, India J Trop Pediatr. 2007; 53(2):98-102.

[12] Cole TJ, Flegal KM, Nicholls D, Jackson AA. Body mass index cut offs to define thinness in children and adolescents, international survey. Bmj. 2007; 335(7612):194.

[13] Cooley D, Oakman R, McNaughton L, Ryska T. Fundamental movement patterns in Tasmanian primary school children. Percept Mot Skills. 1997; 84(1):307-16.

[14] Dempsey T, Miller A. A policy on increasing physical activity in school-aged children. Journal of Oklahoma State Medical Association.2004; 97(3): 119-21.

[15] Gill PS, Prasad GB, Shrivastava RN. Nutritional status of primary school children in a rural area of Lucknow. Indian Journal of Pediatrics.1963; 35(7):314-326.

[16] Graitcer PL, Gentry EM. Measuring children: one reference for all. The Lancet. 1981; 2:297-9.

[17] Gupta PK. Health status of rural school children. Indian Pediatr.1989; 26(6):581-4.
[18] Gupta RK, Bhat A, Khajuria RK, Bhat A. Health status of primary school children in Jammu. Indian Journal of Preventive \& Social Medicine. 1997; 28(3\&4): 90-4.

[19] Khan NI, Singh SB, Hasan SN, Sinha A. Anthropometric measurements in rural school children. The Journal of the Royal Society for the Promotion of Health.1990; (110): 184186.

[20] Mandal GC, Bose K. Assessment of overall prevalence of under nutrition using composite index of anthropometric failure (CIAF) among preschool children of West Bengal, India. Journal Iranian Journal of Pediatrics. 2009; (19)3: 237243,330 .

[21] Medhi GK, Barua A, Mahanta P. Growth and nutritional status of school age children (6-14years) of tea garden worker of Assam. J.hum.Ecol. 2006; 19(2):83-85.

[22] Mondal N, Sen J. Thinness is a major underlying problem among Indian children. J Trop Pediatr. 2010; 56(6):456-8.

[23] Pelletier D.L, the relationship between child anthropology and mortality in developing countries: Journal of nutritional supplement 1994, 124(ios)20475-20815.

[24] Raghava P.K School Health, Indian journal of community medicine 2005,30:1-3

[25] Rajaram S, Sunil TS, Zottarelli LK. An analysis of childhood malnutrition in Kerala and Goa. J Biosoc Sci. 2003; 35(3) 335-51.

[26] Som S, Pal M, Bhattacharya B, Bharati S Bharati P. Socieconomic differentials in nutritional status of children in the states of West Bengal and Assam. J Biosoc Sci 200638 (5): $625-42$.

[27] Une AE, Houmsou, Soumay R. Assessment of nutritional status of school children in Makurdi, Benue state. Pakisthan journal of Nutrition. 2009; 8 (5): 691-694. 